\title{
Electronic Health as a Component of G2C Services
}

\author{
Rasim Alguliyev \\ Department of information society problems \\ Institute of Information Technology of ANAS \\ Baku, Azerbaijan
}

\author{
Farhad Yusifov \\ Department of information society problems \\ Institute of Information Technology of ANAS \\ Baku, Azerbaijan
}

\begin{abstract}
This paper explores electronic health as a segment of electronic government. International practice in electronic health field and electronic health strategies adopted in Europe are analysed. Current practices in delivery of electronic health services in G2C are investigated and perspectives are specified.
\end{abstract}

Keywords-electronic health; electronic government; Government to Citizen (G2C); electronic services; medical information; Electronic Health Records (EHR)

\section{INTRODUCTION}

At present, the active implementation of informationcommunication Technologies (ICT) is observed in various fields of human activity, including in public administration, economy, education and health.

The development in the sphere of ICT and webtechnologies has substantially altered the organization, proposal and delivery of government services [1]. Currently, the establishment and use of new government services is mostly dependent on the development of electronic government (e-government) within the framework of national and international programs, as well as the demand of citizens for online use of electronic services.

More specifically, e-government forming in developed countries is based on electronic interactions of three models Government to Government (G2G), Government to Business (G2B) and Government to Citizen (G2C) [2, 3]. G2C is the expression of mutual relationships between citizens and government, and includes several electronic services (eservices) such as the forming of tax relations, issue of birth certificates, registration and voting by voters, conduct of referendums, provision of medical information. Electronic health (e-health) services delivered to citizens are among services that are approached with special sensitivity. Currently, citizen expectations are being expanded regarding e-services delivered in healthcare sphere such as accessibility of good practice and useful information, improvement of the quality of health services, new treatment methods, delivery of long-term medical support and medical insurance.

In 2000's e-health was used as a general term for explaining the use of electronic tools and electronic data related to information technologies in healthcare sector [4]. It has been reckoned, in a broad sense, that the use of e-health will facilitate the solution of several problems encountered by healthcare system, improvement of the efficiency of health services, and effective organization of management system.

Electronic health - is a broad term and can be defined as the use of electronic tools for the purpose of delivery of information, resources and services related to health protection. Several terms are being employed in e-health sector, among which electronic health record, mobile health, telehealth, telemedicine, electronic education, social networks where health issues are discussed, analysis of medical data and big data can be mentioned $[4,5]$.

The paper considers e-health as one of the segments of egovernment. International practice in electronic health field and electronic health strategies adopted in Europe are analysed. Existing practice and solutions on the delivery of ehealth services in $\mathrm{G} 2 \mathrm{C}$, advantages and problems of e-health are explored.

\section{ELECTRONIC HEALTH SYSTEM}

At present, there is no sole world practice for establishment of e-health system. Even in developed countries several models are proposed for establishment of government e-health system. The model selection depends on financing mechanism and the state of healthcare administration in the country in the first instance. The reforms conducted in healthcare system show that the role of commercially interested enterprises and insurance companies has recently been increasing in healthcare sector [6].

Socio-economic and financial impact and consequences of formation of e-health system have been explored in several thematic research works in Europe. The analysis of prospective spending and expected benefits in e-health system indicate that its socio-economic benefit for the society outweighs the spending in each separate case. The mutual link between e-health data and other clinical-medical systems is considered as the main advantage capable of bringing benefits.

In several research works, it is indicated that the delivery of health services with the implementation of ICT not only provides more advanced health services with lower costs, but also creates broad opportunities which stimulate economic growth. It is, specifically, noted that the application of ICT in healthcare sector will facilitate better quality, delivery of safer health services, the elimination of blunders related to medical drugs and satisfaction of patient needs, and the use of innovative models in delivery of medical aid [7].

It must also be mentioned that, despite several advantages, the application if ICT in medicine is observed to be relatively slower in comparison with the other sectors. Researchers usually explain this matter with the fact that an administration of health services is a complex process. As the main reasons, the requirements of participation of parties of interest, as well as central and local governance entities, doctors and other 
experts in the field of medicine, the availability of medical information, information exchange between parties, the security maintenance and accurate processing of individual information are indicated.

Another important factor is the maintenance of semantic and technical compliance of different systems at local, national and inter-boundary level for the purpose of delivery of high quality health services encompassing the citizens within and beyond the country boundaries.

It is clear from indicated factors that ICT implementation in healthcare sphere requires the conduction of appropriate measures in different spheres (normative, organizational, administrative and technical) at local, regional, national and international levels.

While investigating international practice in e-health sector, it can be seen that one of the goals is the assessment of degree of the implementation of advanced technologies in delivery of e-health services to citizens which accords with European Union strategy and indicators by taking existing problems into account.

\section{ELECTRONIC HEALTH STRATEGIES OF EUROPEAN COUNTRIES}

In 2000, European Union (EU) member countries have adopted "eEurope 2002" initiative in order to use the facilities of Internet and ICT, and the structuring of European state policy in ICT sector have been commenced [8]. One of the primary goals of this initiative was to stimulate the use of Internet as well as to propose the notions of "online government" and "online medicine". In other words, the maintenance of electronic availability of government services and the facilitation of transparency, openness and availability of medical-sanitary information as much as possible were considered by employing new technologies.

In "Electronic Europe 2005" Activity Plan, strategically goals and activity directions have been specified based on the initiatives in e-government and e-health sectors [9]. Its primary aim is directed towards the provision of access to online government services and content, maintenance of user satisfaction, convenience and multiplatform availability, and the delivery of services conforming to the needs of citizens.

In order to achieve these goals, European Commission has proposed several measures such as the maintenance of availability of access to broadband Internet connection, mutual relations between national systems at EU level, delivery of Pan-European e-government services to citizens, the maintenance of secured information structure.

In 2004, European Commission has approved the first action plan on e-health, and the notion of e-health was described as the application of ICT to all functional fields affecting the health sector [10]. In general, ICT-based tools and services facilitating the improvement of preventive measures, diagnostics, treatment, monitoring and administration are included here.

In last 10 years, several plans, strategies, and directives of measures have been adopted and carried out by European
Commission on improvement of e-health sector [8-12]. "Ehealth Action Plan 2012-2020" adopted in 2012 is directed towards the elimination of the obstacles for complete and effective improvement of e-health in compliance with goals of "Europe 2020" program dwelling upon the large potential of e-health [12].

One of the main goals of Action Plan is the creation of route map of e-health based on adopted framework programs, and the maintenance of four-stage (legal, organizational, semantic and technical) relations according to mutual exchange program [12].

The application and improvement of ICT in e-health sector is carried out by DG INFSO competence group (ICT for Health Unit of DG INFSO) at the level of European Commission [13]. This group supports rich data base which stores the information on all issues of EU level policy and scientific research.

Currently, the development tendency existing in e-health sector in European states can be divided into several stages: member states shape the strategy for e-health sector; the standards are developed for Electronic Health Records; moreover, large volume of Patient Summaries are already being stored in 4 countries; e-prescription service is being applied in 3 countries and other countries are at the stage of realization; telemedicine is experimentally implemented at the regional level in Northern European countries; legal issues are being prepared in some countries. Large-scale Pan-European pilot projects are developed based on Electronic Health Records standard [13, 14].

In general, it can be noted that European Commission plans to facilitate the establishment of effective and operative state services in member countries, especially, the expansion of health system by developing this strategy with ICT implementation.

\section{Electronic Health Services IN G2C}

G2C (government to citizens) - mainly covers e-taxes, eemployment, e-voting, e-health and other citizen centric services by reflecting the mutual relations between citizens and the government [1-3]. Amidst the services mostly required by citizens in everyday life in $\mathrm{G} 2 \mathrm{C}$ sector, information, education, e-employment, and e-health services can be mentioned. E-health - is considered as an important sector which is being developed at the crossroads of medical informatics, medicine and business sectors. E-health is attributed to such health services and information which encourages the formation of new information relations between patients and medical experts by being enhanced with the help of Internet and technologies, and by increasing efficiency and raising the quality. At the same time, e-health services are associated with medical experts or medical staff as $\mathrm{G} 2 \mathrm{C}$ services.

Citizens or potential patients search for satisfactory and reliable e-health services proposed by medical experts via appropriate web-pages. E-health provides a mutual link between citizens, patients and medical facilities for information transfer. Several matters such as methods of specification of treatment or therapeutic schedule, the 
accuracy of diagnoses, discovery of experts or entities with desired expertise are attributed to mostly encountered problems [3].

In practice, the following can be considered as the e-health applications:

- Electronic health records;

- Electronic health card;

- E-prescription service;

- Medical information network;

- Telemedicine services;

- Portative systems;

- Portals specialized in health.

Alongside, several other ICT tools can be mentioned for disease prevention, diagnostics, health monitoring and the management of the quality of life.

EU-funded ICT based research and innovation projects addressing societal challenges in the areas management of chronic diseases, surgical treatment to the recovery phase, such as an epilepsy project, a stroke recovery project, patient safety in robotic surgeons', various projects to help surgeons in making critical decisions and other projects from which patients can benefit [15].

One of these projects is EPILEPSIA [16]. The main goal of the project is a brain-computer interface to help patients stay in control. EPILEPSIAE project works to improve the safety and the quality of life of epilepsy sufferers. The project researched the technology of brain-computer interaction and developed an intelligent system capable of collecting and analysing patient's data and predicting epileptic seizures for patients. Also, this system was integrated in a prototype of a transportable alarm device which helps the patient to be in control of their health status.

Another important project is CONTRAST [17]. This project is based on the human (inter) face of ICT to aid recovery after a stroke. This project addresses the gap between clinical rehabilitation and patient support at home.

In practice, the system works as the patient sets up a headset with electrodes connected via the Internet to the assigned doctor's headset. On the basis of information collected from different sources (EEG, heart rate,) the doctor decides together with the patient on the most appropriate training, addressing attention and memory, in particular. Note that results from this project have started being translated into commercial products but some modification is needed for it to be turned into a fully available product in health services as well as in $\mathrm{G} 2 \mathrm{C}$ services.

Another interesting project is PASSPORT which was EU funded [18]. The PASSPORT project is based on using a virtual liver for real patient safety. In this project developed a "virtual liver" that helps surgeons take critical decisions on operating process. Note that, it is a virtual reproduction of the patient liver that enables the surgeon to obtain much of the needed information to decide on the treatment and programme the patient's recovery. One of the interesting moments is that the virtual software used in the project is based on open source technology available online making it easier for doctors to collaborate and share their analysis. In 2015, this service is used in more than 10 different countries with more than 200 clinical cases modelled during the last months. The main benefit is the possibility to optimize preoperative planning, significantly improved in more than $20 \%$ of clinical cases.

One of the important citizen-centric services is a STORK project [19]. This project makes it possible for EU citizens who are resident in a Member State other than their own or work in one country and live in another one to access online public services, wherever, they are located. This project proposes a solution to make it easier for EU citizens to access the relevant public service online wherever they are located. Using electronic-identity authentication system, citizens can access their national electronic identities in any Member State that was participating in STORK. Public institutions can connect their services to the European e-ID interoperability platform in key areas like e-banking, e-health, public services for business and eLearning and academic qualifications.

Considering the international practice, the implementation of special cards is being initiated for the use of health services for the purpose of delivery of e-services in $\mathrm{G} 2 \mathrm{C}$ sector in several countries $[3,20,21]$. It is no coincidence that e-health records are considered as the main element of e-health concept in several European countries. Structured electronic medical documents are collected in these records based on the information transferred from distributed data bases. European epSOS system aimed to design, build and evaluate a service infrastructure that demonstrates cross-border interoperability between electronic health record systems in Europe. The epSOS project was completed in 2014 was indicated as one of the popular projects of information transfer on patient and eprescriptions [22]. In other words, epSOS supported the convergence of the e-health progress in the EU by cooperating and providing the e-health network with the epSOS data set of the Patient Summary and e-prescriptions. Thus epSOS helped the process towards interoperable healthcare in Europe.

Note that, as a next step, the different countries and governments may take up other initiatives to approach the overall goal of establishing an interoperable cross-border healthcare system across Europe. Already, many initiatives (national and cross-border) base their work on epSOS results highlighting that the efforts in epSOS support public healthcare systems and cross-border exchange of information between them, in Europe. epSOS project will ensure that its deliverables are providing enough practical guidance and recommendations on how to make use of its results in a more long-term implementation [22].

At present, a unified information system is being implemented in health sector in Europe. Within the framework of e-government, the establishment of information system segment is considered based on this program. Experts estimate the investment requirement of e-health sector as 21,6-43,2 million dollars in next 10 years. Electronic health records, national information structure in health sector, regional health 
information organizations (RHIOs), electronic exchange of medical data are attributed as the main priorities of currently conducted works [20].

In European practices, electronic health records are realtime, citizen-centric, patient-centred records that provide immediate and secure information to authorized users. Electronic health records typically contain a record of the patient's medical data, results of diagnoses and treatment, medications, information about allergies and immunizations, as well as radiology images and different laboratory results. That is why an electronic health record system plays a vital role in universal health coverage by supporting the diagnosis and treatment of patients through real-time, comprehensive and timely patient information at the point of care.

In World Health Organization (WHO) Report 2016 it is described through project funding, studies, research and policy initiatives that, the EU is active in developing and supporting cross-border interoperability of e-health [14].

As a result, use of international standards to support national electronic health record systems promotes interoperability with other health-oriented ICT systems and with cross-border health services. In order to engage intersectoral partners and patients, integrating with public services, especially G2C services, it is important to better understand the need for sharing health information in the process of electronic health record system development. Also note that appropriate national legislation governing electronic health record systems and their use by the full health and social care team should be defined and local, regional systems should be integrated with national systems.

Note that, most e-Government projects in this area are aimed at facilitating exchanges of information and helping medical staff, doctors, concentrate on care and treatment and nothing else. For example, faster registration of patients at treatment centres.

One of the main stages in the restructuring of the relationship between patients, health and social care staff, professionals and public sector, especially G2C services are obviously the implementation of digital technologies and the creation of e-health cards, also referred as electronic health records.

To summarize the current state of the most important implementations of e-health cards use in the healthcare sector in European countries, France was the first country to launch large scale use of smart cards in the healthcare sector with the Sesam-Vitale system in 1998 [23,24]. The e-health cards initially included only some information about health insurance, but later on complementary health insurance administrative data information was added. Starting from 2007, "Carte Vitale 2" card is implemented in France. These cards are prepared in compliance with IAS (Identification, Authentication and Signature) standard. Vitally important information is stored in this card and it is used as a unique tool for accessibility of health services.
In Germany the health card, electronische GesundheitsKarte (eGK), is often described as one of the largest IT projects in the world, and aims to redesign the way health services are provided. Germany started considering the use of e-health cards in 1996 with the Krankenversichertenkarte, and started development in 2000. In order to benefit from health services, electronic records are implemented in Germany [24]. By creating appropriate infrastructure in healthcare system, the implementation of these cards, the issue of e-prescriptions, also the use of patient's electronic records is facilitated. The card can be used with administrative, as well as medical software. By supporting card operations, administrative software provides the solution to such problems as the control of entitlement to benefit from services and possession of insurance and the issue of electronic prescription. The availability of medical tools for the patient during the use of card is provided by mutual consent. This facilitates the access to information regarding electronic medical records, chronic diseases, allergic reactions and relevant medical data.

Sweden carried out a pilot project related to the large-scale implementation of e-health records [25]. The information regarding patient's individual information, pathologies, chronic diseases, allergic reactions, analysis results, certificates on prescribed medications and other related information is stored in the card. In Sweden, a special organization was created for the project management within the framework of national e-health strategies. It must be mentioned that the organization is directly responsible for the issue of e-prescriptions. The cost of implementation of information technologies in the health sector in Sweden constitutes $2-3 \%$ of healthcare spending.

Healthcare systems in Estonia are considered one of the most developed in Europe [20]. The government of Estonia has created a central database of health and social care. The central database collects information about each inhabitant of the country. The database records disease history from birth till death. Citizens' ID card enables confidential authorised access to all medical information regarding the patient via the www.eesti.ee portal.

Countries throughout Europe are providing their citizens with e-health cards. Some use the cards in their national healthcare programs. Others have smart card based national ID programs as described in Table 1. [23, 24].

From the point of view of practices across European countries, despite the many benefits and opportunities of ehealth cards in the healthcare sector, smart cards have not achieved large-scale use due to several limitations. One of the main limitations is the cost of replacing the existing infrastructure, with e-health card health information services. Furthermore, e-health card implementation requires the agreement between all those involved: public authorities, healthcare providers, health insurance companies and the citizen, and thus demands greater cooperation. 
TABLE. I. EXAMPLES OF E-HEALTH CARD IMPLEMENTATION IN EUROPEAN COUNTRIES

\begin{tabular}{|c|c|c|c|c|}
\hline Country & Card & $\begin{array}{l}\text { Number } \\
\text { Deployed }\end{array}$ & $\begin{array}{l}\text { Laun } \\
\text { ch } \\
\text { Year }\end{array}$ & $\begin{array}{l}\text { Smart card } \\
\text { uses }\end{array}$ \\
\hline Austria & e-card & $\begin{array}{l}11 \text { million } \\
\text { (patient) } \\
24,000 \\
\text { (professional) }\end{array}$ & 2005 & $\begin{array}{l}\text { e-Prescribing } \\
\text { Insurance } \\
\text { check, } \\
\text { e-Referral, } \\
\text { eGovernment }\end{array}$ \\
\hline Belgium & $\begin{array}{l}\text { Social system } \\
\text { identity }\end{array}$ & 11 million & 1998 & $\begin{array}{l}\text { e-Prescribing } \\
\text { Insurance } \\
\text { check, } \\
\text { e-Referral } \\
\text { eGovernment }\end{array}$ \\
\hline France & $\begin{array}{l}\text { Sesam Vitale } \\
\text { Sesam Vitale-2 }\end{array}$ & $\begin{array}{l}60 \text { million } \\
\text { (total) }\end{array}$ & $\begin{array}{l}1998 \\
2007\end{array}$ & $\begin{array}{l}\text { e-Prescribing } \\
\text { Insurance } \\
\text { check, } \\
\text { HER }\end{array}$ \\
\hline Germany & $\begin{array}{l}\text { Gesundheitskarte } \\
\text { (health card) }\end{array}$ & $\begin{array}{l}80 \text { million } \\
375,000 \\
\text { professional }\end{array}$ & 2006 & $\begin{array}{l}\text { e-Prescribing } \\
\text { Insurance } \\
\text { check, } \\
\text { Medication } \\
\text { Log, EHR, } \\
\text { e-Referral } \\
\end{array}$ \\
\hline Hungary & $\begin{array}{l}\text { MOK, } \\
\text { Hungarian } \\
\text { Chamber of } \\
\text { Doctors } \\
\end{array}$ & 40,000 & 2006 & $\begin{array}{l}\text { Insurance } \\
\text { check, } \\
\text { HER } \\
\text { eGovernment }\end{array}$ \\
\hline Italy & $\begin{array}{l}\text { Carta Nazionale } \\
\text { dei Servizi } \\
\text { (national service } \\
\text { card) }\end{array}$ & 3 million & 2004 & $\begin{array}{l}\text { e-Prescribing } \\
\text { Insurance } \\
\text { check, } \\
\text { EHR, } \\
\text { e-Referral }\end{array}$ \\
\hline Slovenia & $\begin{array}{l}\text { Health insurance } \\
\text { card }\end{array}$ & $\begin{array}{l}2 \text { million } \\
\text { (patient) } \\
70,000 \\
\text { (professional) }\end{array}$ & 1999 & $\begin{array}{l}\text { Insurance } \\
\text { check }\end{array}$ \\
\hline Spain & Carte Santé & 5.5 million & 1995 & $\begin{array}{l}\text { Health care } \\
\text { Insurance } \\
\text { check }\end{array}$ \\
\hline Estonia & ID-kaart & 1.2 million & 2002 & $\begin{array}{l}\text { e-Prescribing } \\
\text { national } \\
\text { health } \\
\text { insurance } \\
\text { card } \\
\text { eGovernment }\end{array}$ \\
\hline
\end{tabular}

Currently, the European Health Insurance Card (EHIC) entitles the holder to emergency healthcare cover in European countries. The card was phased in from 1 June 2004 and throughout 2005, becoming the sole healthcare entitlement document on 1 January 2006. Nowadays, a free card that gives citizen access to medically necessary, state-provided healthcare during a temporary stay in any of the $28 \mathrm{EU}$ countries, Iceland, Lichtenstein, Norway and Switzerland, under the same conditions and at the same cost (free in some countries) as people insured in that country [26].

Implementing ICT into health system adds value to the services and to the skills of the medical staff using them. Although significant progress is being made towards citizencentred service models in Europe, critical gaps in the design and delivery of health services remain. Note that, most importantly, effective national health reform needs to adopt the perspective of the patient as citizen in order to understand how e-health tools and services can be used to facilitate better care.

It is clear that the usefulness of e-health in terms of improvement of efficiency of services for both citizens and government, the adequacy of treatment, the reduction in management spending are not possible without the integration of clinical-medical, economic and administrative indicators. From this point of view, timely, accurate, complete and clear information is needed for the analysis of costs and effectiveness, assessment of existing strategy and the conduct of national and international comparisons.

This research facilitates the discovery and sharing of best practice, assessment of quantitative and qualitative indicators of e-health, control of the efficiency of budget resources, determination of successful medical facilities and the improvement of indicators characterizing citizens' health. Moreover, the current information in citizen-oriented systems must be accessible for medical facilities as well as patients, so that both parties can use it in accordance with their needs and requirements.

\section{Advantages AND PROBlems of E-HEAlth}

E-health has significant impacts on the lives of citizens, the working conditions of health personnel (doctors, healthcare professionals and administrative staff) and the activities of health offices and whole e-government system.

In general, the outlook for e-health covers several perspectives: technological, research, economic, political, international cooperation and stakeholders.

Some advantages of e-health technologies are the following:

- Electronic health data is useful for doctors, practitioners and scientists for treatment and research purposes.

- With the advent of innovation and new technologies, multimedia files and data in the form of pictures, videos, and text can be shared in real time on a range of platforms;

- E-health services may play an important role in having more balanced proportion between medical staff and patients all round the world;

- Multi-location real time video-conference can be used to conduct training sessions, treatment of diseases, collaborations, and more.

- E-health resources can be accessed by large number of people to study and to get knowledge about health related issues at their own convenience.

- Possibility using satellite based medical diagnosis and care of elderly in their homes and other.

Main problems of implementation of e-health are the following:

- Lack of concept and national strategy in health sphere specially in developing countries; 
- Uncoordinated efforts between government, public administration and medical facilities;

- Lack of e-health services in realizing strategy of egovernment, as well as in G2C segment;

- Inadequate financing and ineffective organizing;

- Lack of legal framework;

- Confidentiality, privacy, protecting personal information and other issues;

- Lack of universal software platforms in health system in different medical facilities.

\section{CONCLUSION}

Currently, a single world practice does not exist regarding the establishment of e-health systems. Even in developed countries several models are being proposed and trialled for creation of government e-health systems. One of the biggest problems for e-health is the matter of administration of medical facilities and management. Integration of daily data can be very supportive in this regard. The investigation of international practice and the implementation of best practices can help to eliminate such problems.

In this article, e-health is considered as a segment of egovernment while international practice and adoption of ehealth strategies are considered. Perspectives of the delivery of e-health services in $\mathrm{G} 2 \mathrm{C}$ are explored and explained. The study of best practices in this field in future research works will facilitate the expansion of citizen-centric e-services.

\section{REFERENCES}

[1] M. Domenichiello, "State of the art in adoption of e-health services in Italy in the context of European union e-government strategies," Procedia Economics and Finance, No 23, 2015, pp.1110-1118. www.sciencedirect.com

[2] R.M. Alguliyev, F.F. Yusifov, "Some actual scientific and theoretical problems of formation of the electronic government and the perspectives of their solutions," Scientific-practical journal of Problems of Information Society, No 2, 2014, pp. 3-13.

[3] W. Zhang, Y. Zhu, and et al., "Personalized Recommendation of EHealth Services Based on Mutual Information," International journal of innovative computing, information \& control, vol. 11(3), 2015, pp. 903919.

[4] J. Mitchell, "Increasing the cost-effectiveness of telemedicine by embracing eHealth," Journal of Telemed and Telecare, vol. 6 no. suppl. 1, 2000, pp. 16-19.
[5] E-health in practice, www.euro.who.int

[6] World practice of establishment of electronic health in governments, www.cnews.ru.

[7] E. Ronchi, J. Adler-Milstein, G. Cohen, L. Winn, and A. Jha, Better Measurements for Realizing the Full Potential of Health Information Technologies, Chapter 1.7 in the 2013 Global Information Technology Report, World Economic Forum, www3.weforum.org

[8] Council and the European Commission, eEurope (2002): An Information Society for All, 2000, Brussels. www.umic.pt

[9] European Commission, eEurope 2005: An Information Society for All, COM (2002) 263 final, 2002, Brussels. www.etsi.org

[10] European Commission, eHealth - making healthcare better for European citizens: An action plan for a European eHealth Area, COM (2004) 356 final, 2004, Brussels. http://ec.europa.eu

[11] European Commission, i2010 An European information society for growth and employment, COM (2005) 229 final, 2005, Brussels. http://europa.eu

[12] European Commission, eHealth Action Plan 2012-2020 - Innovative healthcare for the 21st century, COM (2012) 736 final, 2012. Brussels. http://ec.europa.eu

[13] Analysis of development of electronic healthcare in Europe, http://zerde.gov.kz

[14] From innovation to implementation, eHealth in the WHO European Region, Report, 2016, www.euro.who.int/en/ehealth

[15] EU funded societal challenges projects, https://ec.europa.eu

[16] Project EPILEPSIAE, A brain-computer interface to help you stay in control, https://ec.europa.eu

[17] Project CONTRAST, The human (inter)face of ICT to recover after a stroke, https://ec.europa.eu

[18] Project PASSPORT, A virtual liver for real patient safety, https://ec.europa.eu

[19] Project STORK, Take your e-identity with you, everywhere in the EU, https://ec.europa.eu

[20] Electronic healthcare as a factor of development of quality and availability of health services to population, 2014, www.dompressy.by

[21] Foreign practice of solution of electronic government building and delivery of government services, http://aisup.economy.gov.ru

[22] epSOS results \& outlook, www.epsos.eu

[23] Smart Cards and Healthcare Providers, www.smartcardalliance.org

[24] A.P. Keliris, V. D. Kolias and K.S. Nikita, Smart Cards in Healthcare Information Systems: Benefits and Limitations, IEEE 13th International Conference on Bioinformatics and Bioengineering (BIBE), 2013, www.computer.org

[25] A.A. Kukhtichev, "Electronic health records as a basis of ehealth services of information system "digomed"," NSU News, Series: Information technologies, vol.14, № 1, 2016, pp. 61-75.

[26] European Health Insurance Card, http://ec.europa.eu 